\title{
1. Introduction: valuing environments in the rich world
}

\section{David Pearce}

\section{BACKGROUND}

This is the second of two volumes of case studies aimed at showing how environmental economists place value on environmental assets and on the flows of goods and services generated by those assets. The first volume looked at valuation exercises in the developing world (see Pearce et al. 2002). The current volume focuses on the developed, or rich world. This is where the first exercises in economic valuation began. The aim has been to assemble studies that show the very broad areas of application of economic valuation, from amenity and pollution through to water and health risks, from forestry to green urban space. As with the first volume, the chapters come from authors who, at one time or the other, formed teams of environmental economists at University College London. But other UK and continental European economists have been invited to contribute in order to capture the wide array of applications.

All the chapters in this volume take it as read that economic valuation makes sense. Since that is not a view shared by many non-economists, it is as well to devote a short space to explaining what economic valuation is and why it is a rational procedure.

\section{ECONOMIC VALUE AND ITS CRITICS}

The notion of economic value has a very precise meaning. It relates to human well-being. Changes in well-being are revealed by people's preferences. Basically, if someone prefers A to B, their well-being from A is said to be higher than their well-being from B. In common with utilitarian philosophy, the notions of costs and benefits and asset values relate to the sum of these individual economic values. It is assumed therefore that it makes sense to add up what individuals prefer to get some aggregate, which defines the 
social value of the asset. Also, an individual's well-being is assumed to be measurable through the notion of willingness to pay. Essentially, if someone prefers A to B they will be willing to pay more for A than for B. The extra (marginal) willingness to pay is what is measured by a demand curve. The problem in environmental economics is that many environmental goods and services have no markets, or at least no obvious market. Hence demand curves have to be 'uncovered' by looking for surrogate markets or by creating a market. The former procedure is 'revealed preference' and is typified by something like hedonic property pricing whereby the value of, say, noise nuisance or air pollution, is measured by the price depreciation suffered by properties exposed to these damaging influences. The latter procedure is 'stated preference'. A hypothetical market is established through the use of questionnaires and respondents are either directly asked for their willingness to pay, or it is inferred from their stated choices.

One reason that some critics dislike this notion of economic value is that it looks altogether too much like buying and selling goods in the supermarket. And, of course, it is. Indeed, the whole aim is to put environmental goods and services into the same framework as buying and selling marketed goods and services. The objection of the critic is that this somehow 'debases' the environment to being just another good, like a car journey or a hamburger. Surely, the environment is somehow 'above' this comparison? It is possible to have some sympathy with this view. If people do not like (prefer) the environment, then economic analysis suggests it should be dispensed with. But there are problems with any view that tries to make the environment 'different' or 'special' and outside the scope of economic value.

First, saying that economic value should not count is the same as saying people's preferences should not count. That is undemocratic and, indeed, the main defence of economic valuation is that it embodies a 'democratic presumption'. What the critics are really saying is that some elite (usually themselves!) possesses the right values and only they should decide what happens to environmental assets. Any environmental economist with any practical experience of government will be familiar with that view, which is usually expressed by unelected members of special interest organizations.

Second, economic values derive from trade-offs, from the fact that we cannot have everything and hence have to choose. To say economic values are inapplicable to environmental assets is therefore formally equivalent to saying we can never trade off those assets against other goods and services. One observation is that such trade-offs are made every day and no society anywhere in the world operates as if such trade-offs cannot be made. It is easier to be sympathetic to the view that this trading off has gone too far, that, in some sense or other, we now have 'too little' environment and that no further degradation should be permitted. But it is not very clear what 
this constraint on trade-offs means. It cannot mean never cutting down one more tree, nor can it mean holding the physical stock of environmental assets constant since we have no metric to measure that stock in physical terms, and hence no way of knowing if the constraint is being observed or not. The constraint could be expressed in monetary terms, that is, the economic value of the stock should be held constant. But this is where we came in and such a rule offends the value critic because we have now ended up measuring the environment in economic value terms. The critic of economic valuation therefore has many more problems to address before his or her criticisms become robust.

The critics also argue that economic value, if it is permissible at all, is only one value among many. There are also aesthetic values, spiritual values, social values (sense of identity and space), historical values, symbolic values and intrinsic values (and probably others, too). The problem with this line of criticism is that it is not very clear how these values are to be defined. More importantly, how do they enter the policy context? If we always have to make choices (trade-offs) how does, say, spiritual value trade off against economic value? Does it always trump economic value? If there is a tradeoff, how does one trade off a non-measurable notion of value (spiritual value) against a measurable one (economic value)? Part of the problem is that the critics occupy a world in which these choices do not have to be made by them. As the guardians of their own notions of value, their own interpretation of that value is always 'right'. Moreover, unlike those arguing for economic value, the critics need to have no recourse to what the ordinary citizen wants. The democratic presumption issue arises again.

Some of the critics argue that the environment is rather like human life: it is 'priceless'. Several recent critiques of economics adopt this view - for a recent well written, but wholly misconceived, critique along these lines see Ackerman and Heinzerling (2004). In the 'priceless' argument something like environment cannot be brought into the same commensurate units as willingness to pay. But there are several problems with this view.

First, if one cannot compare costs and benefits in commensurate terms, it is hard to know how much to spend on the activities that generate them. If benefits are in some non-monetary units and costs are in money terms, then the only techniques available for rational decision-making are 1. leaving it to political judgement and 2. some sort of cost-effectiveness analysis. But the reason policy analysts develop procedures like cost-benefit analysis is to 'check' on political judgement. Assuming that political judgement is always 'right', without the need for any such checks, makes policy analysis redundant. No doubt many politicians would prefer to occupy such a world, but most people would acknowledge that we need the checks and balances that come from policy analysis. The political judgement view is 
also 'Panglossian' - everything is for the best in the best of all worlds, and political judgements cannot be bettered.

As to the second apparent escape from cost-benefit analysis, costeffectiveness analysis is certainly valuable. Indeed, economists would assume that all decisions subsume cost-effectiveness analysis, otherwise one would be wasting resources to achieve a given end. But cost-effectiveness cannot tell us how much conservation to do. The reason is simple. Costs are not in the same units as benefits. Hence one can never say that benefits 'exceed' costs, we can never know with cost-effectiveness analysis whether anything is worth doing at all.

Second, no nation functions by assuming that assets, of whatever kind, are 'priceless'. Nations go to war, which means that they judge the ends (benefits) to be worth the loss of life that war entails. No nation spends resources to bring risks to life down to zero, so costs are being traded against life risks. No nation conserves each and every environmental asset. Logically that means that conservation is traded against cost. The impossibility of not trading environmental, cultural and life assets against money was pointed out 40 years ago by Thomas (1963). All decisions have costs and hence all decisions to incur that cost imply that benefits exceed costs. All decisions not to incur the costs imply that costs exceed benefits. Economic valuation is always implicit or explicit, it cannot fail to happen at all.

A further critique of the notion of economic value argues that the values relevant to environmental assets are those of the citizen, not the individual. The difference is that when voting as a citizen the individual is supposed to think about the social good in general and not about individual selfinterest. Citizen preferences are not therefore revealed in the market place, nor even in a hypothetical market place such as that embodied in stated preference techniques. Rather one has to look to the political process for evidence on these preferences. This view is perhaps best associated with the writings of Mark Sagoff (for example, Sagoff, 2004). Here again there are problems. The problems with relying on the political process to reveal citizen preferences were noted above. The additional difficulty in this case is that political decisions are invariably the result of 'political welfare functions', which reflect partly what people want, but more what special interest groups and lobbies want. One cannot assume that citizens' preferences determine political outcomes at the level of detail that would be required.

Finally, consider the notion of 'intrinsic value' as a value residing in environmental assets: the assets are 'worth' something in themselves and independently of the human being who may value them. If the 'right' way of thinking about environmental assets is in terms of their intrinsic value, then economic value is at best subservient and at worst irrelevant. Philosophers have debated notions of intrinsic value for centuries. Whether 
it exists or not as a meaningful concept, that is, whether there can be 'value' independently of a 'valuer', is an issue we do not dwell on here. But it is relevant to ask what the policy implications of such notions are, assuming they are meaningful. As we saw, the attraction of the economist's notion of value is that it is commensurate with costs and costs are unavoidable in the decisions to conserve, enhance, modify and manage environmental assets. Non-monetary notions of value can still fall within the domain of cost-effectiveness analysis and this is an essential requirement for rational policy-making.

The practical problem with 'intrinsic value' is that it cannot be brought within the domain of a valuer and hence cannot be measured at all. The implication is that intrinsic value fits neither the economic value concept (deliberately so) nor the cost-effectiveness paradigm. It is also unclear exactly what role it could play in decision-making. Decision-making is about priorities and unless one can say that X has 'more' or 'less' intrinsic value than $\mathrm{B}$, no one can say whether $\mathrm{X}$ should have priority over $\mathrm{B}$, or vice versa. The practical issue, therefore, is not whether intrinsic value exists, but what use can be made of it if it does exist. If it exists and cannot be measured, then perhaps the only way in which intrinsic value can influence decisions is through the decision-making discourse. That is, it would be up to those who wish to argue for more resource allocation to particular assets that they have 'high' intrinsic value, without there being any obligation to measure this notion of value. That takes us back to the problem of political welfare functions and special interests. Intrinsic values are therefore extremely problematic.

The 'standard' economic approach would reject notions of value that are different from economic value. However, it is important to understand why. The standard approach does not argue that other values are irrelevant. What it would argue is that all of these other values are determinants of economic value, rather than values in themselves. In the language of economic valuation, they are motives for value.

A further argument for treating environmental assets differently from other goods and services is that they may be irreplaceable in the sense that, once lost, the original cannot be recreated. The degree of irreplaceability is perhaps more severe for built heritage than it is for environmental assets. Apart from the extinction of species and, say, primary forests, many environmental assets can be recreated with barely discernible differences from the original. The question is whether irreplaceability makes some assets special in the sense of making them a challenge for economic valuation (or even incapable of economic valuation).

But even if an asset is irreplaceable, it does not mean that it has no substitutes. Substitutes may not be perfect, but economic analysis makes 
no assumption about perfect substitutability between money and conventional goods. Rather, perfect substitution is itself a special case. There are two senses to substitution here. First, one environmental asset may be a partial substitute for another environmental asset. That is, there may be 'within-asset' substitution. Second, any given environmental asset may be substitutable, partly at least, by non-environmental assets. In the sustainable development literature, the second notion of substitutability is known as 'weak sustainability'. The former, in which the loss of one environmental asset could be compensated by another environmental asset is known as a 'strong sustainability constraint'. However, since one cannot recreate irreplaceable assets, compensation via the creation of assets is not possible. Strong sustainability would therefore require that each and every irreplaceable environmental asset be conserved. Provided a strong sustainability stance is adopted, the relevance of irreplaceability for valuation is that far stronger pressure exists to conserve everything there is that could be called irreplaceable than in the weak sustainability context. That pressure translates into higher implied values for the marginal environmental asset. In contrast, the weak sustainability paradigm is consistent with the cost-benefit approach in which all kinds of assets are substitutable to some degree. On this paradigm, the values elicited by economic valuation techniques are the relevant ones, that is, the various willingnesses to pay to conserve the assets.

There is a potential implication of irreplaceability for the way in which decisions about environmental assets are made. Suppose some environmental assets are at risk because conservation budgets are limited. Suppose further that the assets at risk are not fully documented, in the sense that further information about them could be generated by more research etc. There are opportunities for 'learning', that is, for generating more information. Then, economic analysis tells us that the combination of uncertainty, the opportunity for learning and irreplaceability, should dictate a more cautious approach to the conservation decision. The value of the information generated by waiting before allowing the asset to decay or be replaced is known as 'quasi option value'. What the quasi option value literature is telling us is that one cannot simply compare costs and benefits of conservation in the conventional manner (deriving a discounted present value based on expectations about future economic values) if the context is one of irreplaceability and uncertainty, and if there is the chance of learning. If everything is known about the asset, then quasi option value does not effectively arise - being cautious about losing the asset will not generate new information.

Overall, then, while the notion of economic value is not without its own problems, it does have a long history, and it would be surprising if those who developed it had not thought about the criticisms made against it. The 
argument here is that those criticisms are far more problematic than those who advance them might think.

\section{COSTS AND BENEFITS}

The case studies in this volume illustrate the wide array of environmental issues that have been addressed using the notion of economic value. By and large they focus on measuring the benefits of an environmental improvement, or the damage done by environmental degradation. From a policy standpoint, one of the weaknesses of the past few decades of economic valuation studies is that they have focused heavily on benefit or damage measurement, rather than on comparisons of these measures with the costs of environmental improvement, or the benefits of the damaging activity. In short, full-blown cost-benefit analysis is less common than benefit measurement.

One reason for being concerned about this asymmetry is that it fails to provide the environmental economist with the full array of weapons in the policy context. All too often, what the Minister of Finance wants to be persuaded of is that investing in the environment achieves as high a social rate of return as investment in other forms of national wealth. In other words, most policy contexts are defined by a general suspicion that the environment is not a national priority and that other things matter more. When it comes to public infrastructure, roads and airports and the like, the presumption is that the environmental impacts are less important than the benefits in terms of the national economy. Those concerned with raising the profile of the environment therefore need to remember that it is both costs and benefits that matter.

\section{VALUE TRANSFER}

Nonetheless, it is easy to understand why environmental economists have focused on benefit and damage estimation. First, the 'value critics' discussed in the previous section place the onus on the economist to show that economic value exists, is relevant to policy-making, and can be measured. Many valuation studies are therefore about showing that economic value is measurable. Second, as the essays in this volume show, the science of valuation has developed rapidly in the past few decades. Many case studies are designed to test the valuation theory and to advance it. The policy implications have been a lower order priority. Where case studies have been designed to answer policy questions they tend to be a mix of rough-and- 
ready analysis and sophisticated analysis. Many of the rough-and-ready studies adopt 'benefit transfer' as the mode of analysis, that is, assets, goods and services are valued in terms of values already demonstrated for similar assets, goods and services in previous studies.

This process of benefit (or value) transfer is potentially dangerous. It is only recently that environmental economists have begun to test for the size of the error that is likely to be involved in 'borrowing' numbers. The search for large 'value databases' - in which studies and their results are stored and accessed - adds to the risks, since it encourages the idea that values can be borrowed and transferred with a reasonable degree of accuracy, without anyone being sure that this is the case. Some of the chapters in this volume (notably those by Clinch (Irish forestry, Chapter 2), Crabtree (UK forestry, Chapter 3), Söderholm and Sundqvist (energy externalities, Chapter 8), Horton and Fisher (water in the UK, Chapter 12), and Newcombe, Özdemiroğlu and Atkinson (agricultural accounts, Chapter 18)) use or comment on transferred values. Chapter 13, by Willis and Scarpa, casts doubt on the large-scale value transfer exercise discussed by Horton and Fisher (Chapter 12). Nonetheless, it is hard to see how value transfer can be improved until original studies are designed with value transfer in mind. At the moment, the 'jury is out' on the likely size of error in value transfer. Much more work is needed.

Value transfer can be advanced through 'meta-analysis', an analysis of the various studies that have analysed economic value of a specific environmental asset, forests or wetlands, say. Meta-analysis usually involves statistical techniques that attempt to explain why the various studies come up with different values. It is not only the characteristics of the assets in the original studies that matter, the characteristics of the studies themselves also matter. Thus, it may matter if the studies have been carried out using particular valuation methods. For example, in a stated preference study it may matter if a telephone survey has been used compared with a face-to-face questionnaire. It may even matter who has conducted the studies. The study by Hall, Moran and Allcroft (Chapter 6) illustrates this kind of meta-analysis in the context of perceived risks to consumers from genetically modified food. A form of meta-analysis, but this time with less focus on statistical assessment, is also provided by Brouwer in his overview of valuation studies in the Netherlands relevant to the European Water Framework Directive (Chapter 7).

\section{THE PRIMARY STUDIES}

The remaining chapters show how 'primary' valuation is conducted, that is, they show how the various techniques that have been developed are 
applied to specific environmental assets. Groom, Hepburn, Koundouri and Pearce (Chapter 5) look at an interesting development in environmental economics, namely the idea that the discount rate is not a constant with respect to time, but actually declines with time. Time-varying discount rates overcome those objections to economic valuation based on its apparent discrimination against future generations. This 'tyranny of discounting' arises simply because people prefer the present to the future, with the result that investment in long-term environmental protection - as with global warming control - appears to have a low economic value.

The other chapters on primary valuation procedures adopt variants of stated preference approaches to valuation, usually contingent valuation but occasionally choice modelling. The former asks respondents directly for their willingness to pay, the latter infers willingness to pay from choices that individuals make across composite goods that are described by 'bundles' of characteristics. Christie and his colleagues tackle the complex issue of valuing biodiversity (Chapter 4) where biodiversity is construed as the diversity of life forms, rather than just a stock of biological resources. Ek (Chapter 9) analyses Swedish preferences for windpower, finding, perhaps unsurprisingly, that there are strong preferences for it as long as it is offshore! Atkinson, Day and Mourato (Chapter 10) focus on another neglected issue - visual disamenity from overhead transmission lines. It is an interesting feature of private sector decision-making that corporations show little interest in finding out what the public actually wants by way of avoiding the disamenity that corporate activity generates. This stands in contrast to their espousal of market research when selling their products. Yet market research and stated preference valuation have very close similarities, the main distinction being that market research focuses on private goods, so that buyers can choose to buy or not once the good is available, and stated preference focuses on public goods that, once available, are available to all without further choice. The transmission line study shows that it is perfectly possible to find out people's preferences for 'undergrounding' (burying the cables) and, given that 'overgrounding' is much cheaper, what people's preferences are for various styles of transmission tower.

Bullock (Chapter 11) adopts a choice modelling approach to valuing urban green space in Dublin. Willis and Scarpa (Chapter 12) summarize what is probably one of the most sophisticated choice modelling studies in Europe. This was conducted for a major private water company in England (Yorkshire Water), which showed the imagination to commission the work in order to find out how its customers valued the various services provided by the company. As noted above, this visionary approach contrasts starkly with how most private corporations approach their wider social and environmental impacts. Chapter 14 by Mourato and colleagues describes another English 
water company initiative in finding public preferences for reducing the risks of sewage overflows into the River Thames in London, a legacy of long-past sewer infrastructure decisions. They also use a choice modelling approach, as do Söderholm and Sundqvist in their own evaluation of energy externalities (Chapter 8). Bateman and colleagues (Chapter 15) use contingent valuation (with a twist!) to value the benefits of reduced eutrophication in water bodies in Eastern England. Chapter 16, by Mourato and colleagues, raises some questions about the suggested strengthening of the European Union Directive on bathing waters. It is interesting that, despite the clear requirement for the European Commission to carry out cost-benefit studies of each Directive, comparatively few are actually conducted or funded by the Commission itself. These essays all show the power of stated preference approaches to elicit economic values that, a few decades ago, would have been regarded as being incapable of economic valuation.

Day and colleagues' chapter on noise nuisance shows the power of another widely used valuation technique, hedonic property price analysis (Chapter 17). The basic idea is simple, property prices reflect the many characteristics of houses, so that the overall price is itself an amalgam of a set of individual (hedonic) prices for these characteristics. Day's study employs powerful econometric techniques to explore these values. In theory, hedonic prices are not quite the same as the economic value of the change in the asset in question (in this case, peace and quiet), but many empirical studies have adopted hedonic prices as the best guess at the relevant economic values.

The last two chapters explore the use of valuation in wider accounting exercises. It is well known that conventional measures of economic output, such as GNP, are potentially poor indicators of well-being. This explains the drive for better accounting systems that try to measure the externalities involved. In their study, Newcombe and colleagues (Chapter 18) report on an exercise that provides the first set of reasonably rigorous economic accounts for UK agriculture. In their study, Brouwer and colleagues (Chapter 19) illustrate a further application of economic accounting, this time focusing on the information needed to understand economic and environmental interactions at the river basin level.

Overall, this volume brings together leading experts in the field of economic valuation, showing just how sophisticated techniques have become and how powerful their application can be.

\section{REFERENCES}

Ackerman, F and L. Heinzerling (2004), Priceless: On Knowing the Price of Everything and the Value of Nothing, New York: The New Press. 
Pearce, D., C. Pearce and C. Palmer (2002), Valuing the Environment in Developing Countries, Cheltenham, UK and Northampton, MA, USA: Edward Elgar.

Sagoff, M. (2004), Price, Principle and the Environment, Cambridge: Cambridge University Press.

Thomas, H. (1963), 'The animal farm: a mathematical model for the discussion of social standards for control of the environment', Quarterly Journal of Economics, 77, 143-8. 
David Pearce - 9781847201768 Downloaded from PubFactory at 04/26/2023 $04: 01: 25 \mathrm{AM}$ via free access 